\title{
Manuel Johnson's tide record at St. Helena
}

\author{
David E. Cartwright ${ }^{\dagger}$, Philip L. Woodworth ${ }^{1}$, and Richard D. Ray ${ }^{2}$ \\ ${ }^{1}$ National Oceanography Centre, Joseph Proudman Building, 6 Brownlow Street, Liverpool L3 5DA, UK \\ ${ }^{2}$ National Aeronautics and Space Administration, Goddard Space Flight Center, Code 698, Greenbelt, \\ MD 20771, USA \\ $\dagger$ deceased, 2 December 2015 \\ Correspondence to: Philip L. Woodworth (plw@noc.ac.uk)
}

Received: 16 November 2016 - Revised: 21 February 2017 - Accepted: 1 March 2017 - Published: 27 March 2017

\begin{abstract}
The astronomer Manuel Johnson, a future President of the Royal Astronomical Society, recorded the ocean tides with his own instrument at St. Helena in 1826-1827, while waiting for an observatory to be built. It is an important record in the history of tidal science, as the only previous measurements at St. Helena had been those made by Nevil Maskelyne in 1761, and there were to be no other systematic measurements until the late 20th century. Johnson's tide gauge, of a curious but unique design, recorded efficiently the height of every tidal high and low water for at least 13 months, in spite of requiring frequent re-setting. These heights compare very reasonably with a modern tidal synthesis based on present-day tide gauge measurements from the same site. Johnson's method of timing is unknown, but his calculations of lunar phases suggest that his tidal measurements were recorded in Local Apparent Time. Unfortunately, the recorded times are found to be seriously and variably lagged by many minutes. Johnson's data have never been fully published, but his manuscripts have been safely archived and are available for inspection at Cambridge University. His data have been converted to computer files as part of this study for the benefit of future researchers.
\end{abstract}

1

The rapid rise to scientific fame of the young Manuel John Johnson (1805-1859), from Second Lieutenant in the East India Company's artillery at St. Helena to world-class positional astronomer and President of the Royal Astronomical Society, is well documented (Warner, 1982). His initial rise was largely due to his star catalogue compiled at the shortlived St. Helena Observatory, for which he was awarded the Gold Medal of the Royal Astronomical Society in 1835 (Johnson, 1835). Much less, in fact practically nothing, has been written about Johnson's earlier recording of the ocean tides at St. Helena, for which he devised a simple but unique instrument and supervised its use, day and night, for at least 13 months from 1 October 1826 to 31 October 1827.

There are several possible reasons for this neglect, but the principal one is Johnson's failure, (possibly due to his fading interest), to obtain adequate publication of his tidal data. Warner (1982) mentions a published "study of the tides at St. Helena", but "study" is a misnomer for a partial tabulation of the data from November to May without introduction, commentary, or even a description of the instrument used. This tabulation concludes with the words: "To be continued in our next Number", but in fact no continuation was printed, and the next volume turned out to be the last of a series (Anonymous, 1829).

The complete 13-months tabulation (excepting a few short intermissions in the period March-May 1827), together with a description of the instrument, exists only in a series of large manuscript sheets, that were held in the archives of the Royal Greenwich Observatory, and have since been transferred to the archives of Cambridge University Library. They are included in the "Papers of George Airy" (Ref. RGO 6/500). It is not known exactly when the manuscripts came into the possession of Sir George Airy, but he was known to have been particularly interested in the tides before his main publication on the subject (Airy, 1845). A partial copy of the data from October 1826 to May 1827 is also held in the archives of the Royal Society of London (Ref. MA/2). 
The object of the present paper is to ventilate this forgotten material and to evaluate the quality of Johnson's measurements.

\section{Other tidal records from St. Helena}

There have been many scientific expeditions to this remote island, mostly by astronomers and geophysicists. The first and most famous of these was the astronomer Edmond Halley, who, while still an Oxford undergraduate, stayed on the island for a year to record the positions of over 300 stars from a temporary observatory high inland (Tatham and Harwood, 1974; Cook, 1998). The first to record the local tides was the Rev. Nevil Maskelyne. The essential object of Maskelyne's expedition was to time the transit of Venus across the sun's disk on 6 June 1761. The transit was obscured by clouds at St. Helena, although successfully recorded elsewhere. Maskelyne's exercise in tide recording, from 12 November to 22 December 1761, partly compensated for the failure of his main objective (Maskelyne, 1761).

On occasions one hears statements that the tide had been recorded at St. Helena as early as 1661 . However, the source of this erroneous statement is a misprint for 1761 in a list of places where the tidal "Establishment" was then known in Lalande's Astronomie, a famous and usually reliable source for the history of astronomy and tides (Lalande, 1781). It also misprints 1662 as the date of publication of Maskelyne (1761).

The theory of tides in 1761 was still rudimentary. Newton had shown that the ocean tides were a natural consequence of his gravitational theory, but the dynamic details were quite unknown, and there was a dearth of observational data, especially in remote parts of the ocean unobstructed by land and shelf seas. St. Helena was ideally remote, but its very exposure to swell waves without harbour protection made observation of the tidal rise and fall very difficult. The one regular landing place at Jamestown (Fig. 1) is in the lee of the predominant South-East Trade Winds, but it is frequently pounded by heavy swell waves, known locally as rollers or surf, originating from storms in the Atlantic and Southern oceans.

Maskelyne eliminated the effect of swell waves by reading from a graduated vertical staff many times over the course of a few minutes and recording the average reading: "I therefore generally made 40 or 50 observations, and sometimes more than 100 , if the rise and fall of the water seemed very irregular". The resulting averages made a smooth progression in time, and simultaneous readings by Maskelyne and his assistant Charles Mason agreed consistently to better than half an inch $(12 \mathrm{~mm})$. Their observations were maintained over all states of the tide for 40 consecutive days and nights, except for 2 days' interruption when the rollers were so large as to cause damage to the vertical staff. (Charles Mason (17301787), an Associate of the Royal Society of London, had ob-

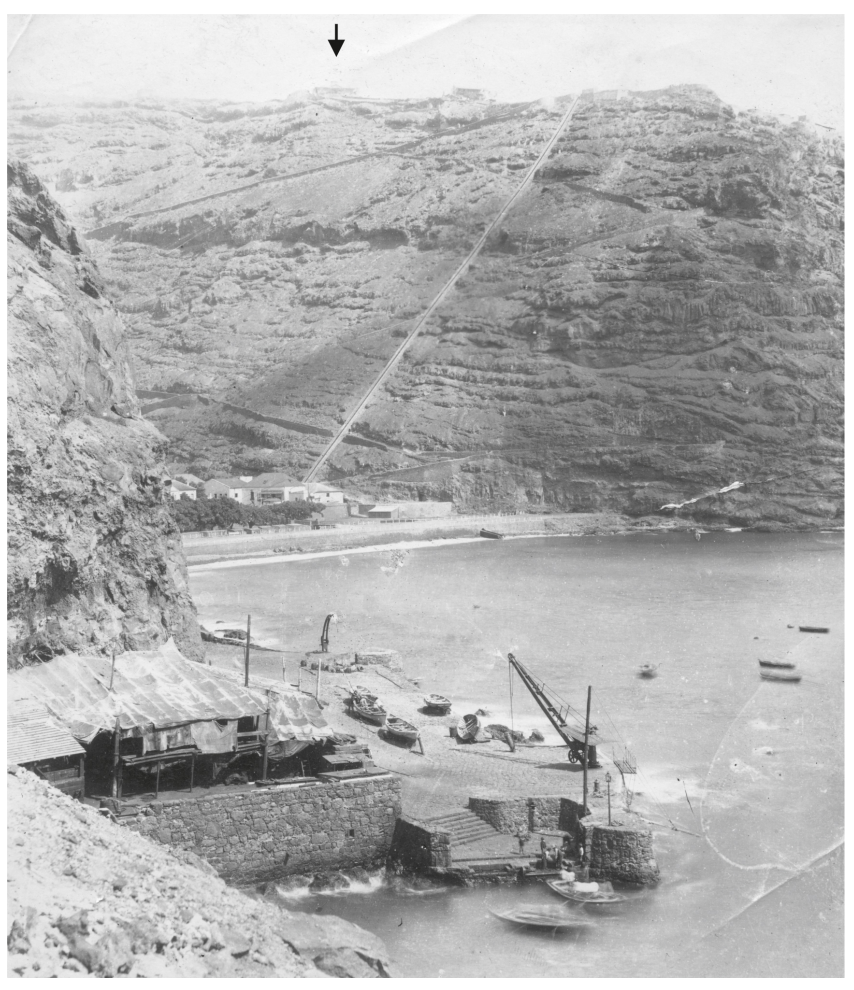

Figure 1. A photograph of the sea frontage of Jamestown, St. Helena, taken around 1903 by Thomas Jackson. The view is from Munden's Point, looking slightly west of southward. All tidal observations have been made in the locality of the landing steps. The astronomical observatory (no longer in use at the time of the photograph), is just about visible on the skyline, marked by an arrow. The straight course of Jacob's Ladder, (699 steps), linking the two areas, is clearly visible. Jamestown Castle is hidden from view by the cliff in the foreground. Jackson was the husband of Emily L. Jackson, an author (Jackson, 1903) who encouraged the development of lace-making as an island industry. (Photograph courtesy St. Helena Museum).

served the 1761 transit of Venus from the Cape. He is best known as the leading surveyor of the Mason-Dixon Line and in the measurement of a degree of latitude in North America.)

Manuel Johnson's tidal observations from the same site started just 65 years after Maskelyne's and Mason's. They were intended as an improved recording, in that waves were damped by a stilling well. Measurements at the high and low waters were recorded semi-automatically for more than a year. Johnson's stilling well and the measurement procedures, as far as they are known, will be described below.

We then jump one and a half centuries to refer to recent records of sea level variations at St. Helena obtained with modern instrumentation. A first excursion, in 1969, was led by Cartwight and Driver from the National Institute of Oceanography (NIO) (Cartwright, 1971a). The main objective was to record tides, swell waves and medium-frequency waves $(1-30 \mathrm{mHz}$ ) from bottom-mounted electrical pressure- 
transducers, one of the mountings being close to the landing place shown in Fig. 1. Continuous records were made from 3 November to 9 December 1969, about the same duration as Maskelyne's exercise, 208 years previously. In 1986, the Institute of Oceanographic Sciences (IOS, the successor to the NIO, subsequently renamed the Proudman Oceanographic Laboratory and now part of the National Oceanography Centre, NOC) sent technicians led by Robert Spencer to Ascension and St. Helena, to install permanent recorders of tides, sea level and atmospheric pressure variation, as part of a growing global network of sea level recording stations (Spencer et al., 1993). This modern installation at St. Helena is again very close to the same landing place, and has given a high-precision record with 15 min or more frequent sampling ever since, although with inevitable interruptions due to the difficulty of regular access for maintenance. Swell waves are eliminated from the record by digital temporal averaging. Analysis of this long record makes an excellent basis for evaluating Johnson's 19th century record.

\section{General Walker and the St. Helena Observatory}

The Emperor Napoleon Bonaparte was kept prisoner at St. Helena from October 1815 until his death in May 1821. Thereafter, there was little for the island's militia to do except guard his tomb. A new Governor appointed in 1823 by the Honourable East India Company (HEIC), Brigadier-General Alexander Walker, had ideas for furthering education in the island, and, as far as his own troops were concerned, he set up a "Military Institution" with courses in languages, geography, mathematics, astronomy and other subjects (Tatham and Harwood, 1974; Warner, 1982). The instructors were selected from the best educated and brightest officers, and they included among others 2nd Lieutenant Manuel J. Johnson, who in 1823 was only 18 years old (Fig. 2).

Besides the Military Institution, General Walker had been persuaded by captains of visiting ships of the desirability of a small observatory to give accurate time for ships' chronometers and to survey the southern stars as an aid to the navigation of HEIC ships (Warner, 1982). The HEIC promised to pay for the building and astronomical equipment, and Walker was so impressed with Lieut. Johnson's zeal, knowledge and ability that in due course he appointed him officer-in-charge of the future observatory. Later, in 1827, Walker appointed Johnson as his "Aide-de Camp".

We know little about Johnson's educational background, other than that he was trained in England at Addiscombe Military College, which prepared young men for service in the HEIC. Even assuming that he acquired there a first class knowledge of the theory of astronomy, this does not automatically qualify a person to set up an observatory or deploy its measuring instruments. One must assume that General Walker was able to supply Johnson with suitably specialised textbooks and records of procedure as at the Royal

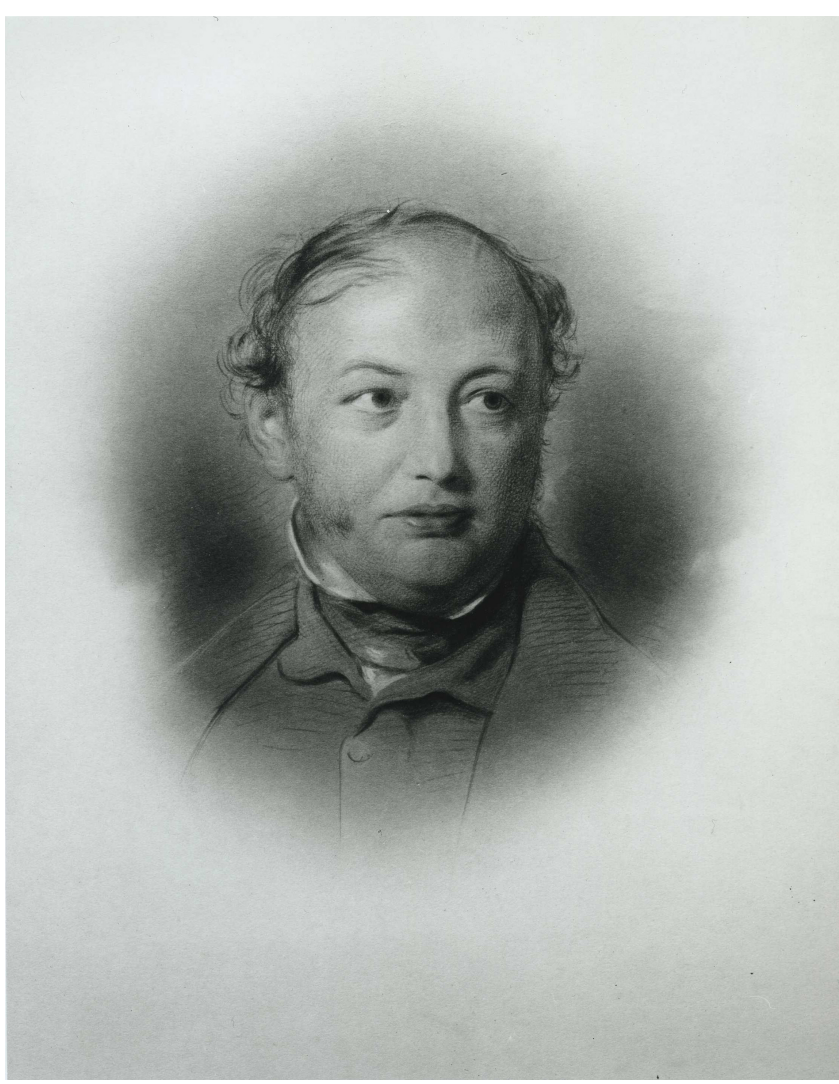

Figure 2. Manuel Johnson (1805-1859), President of the Royal Astronomical Society 1855-1857. Date and artist unknown. (Image courtesy RAS).

Observatory in Greenwich, for preliminary study. There existed on the island basic instruments for astronomical and meteorological observation at Jamestown Castle near the sea. Johnson took a leading part in such observations, which included lunar and solar eclipses. (These astronomical measurements in Jamestown are mentioned in a note from Lt. J. J. Pritchard to General Walker of 1 July 1825 , transcribed in Warner, 1982. Pritchard was then in charge of the Military Institution.)

By December 1825, Johnson was ready for a 3-month trip to the then-new observatory at the Cape of Good Hope, whose Director, the Rev. Fearon Fallows, was able to advise him on the practicalities of his task at St. Helena and on the sort of observations he could most usefully perform.

As a professional astronomer, Fallows was impressed by Johnson's knowledge and dedication and he wrote a glowing letter to Walker, approving his suitability for the post. This letter of recommendation, dated 4 March 1826, is transcribed in Warner (1982). Among his recommendations for suitable work, Fallows made the unusual suggestion that a long record of the ocean tides should be made. He considered St. Helena to be "a place peculiarly adapted for observing the tides. The distances of the island from any other land 
and its small size renders the influence of the heavenly bodies less liable to obstruction. An accurate course of observations made here would therefore be of considerable use in correcting the present Theory". Johnson reported the same in a note to Walker of 21 March 1826, transcribed in Warner (1982), see also Warner (1995). A later Report to the Governor from Lieutenant J. J. Pritchard (Johnson's senior) states the following:

A very excellent gauge has been constructed near the lower Landing Place in Jamestown and the observations are now regularly making. Our attention has been directed to the tides in James' Bay, but may hereafter be extended to the windward coast. They agree as to the high water times at Full and Change [of the moon] with those published by Dr. Maskelyne but re. Rise and Fall our results have been somewhat different (Military Consultations, 1826).

Three points in Pritchard's report deserve further comment:

1. Since the report was filed under 2 October 1826, it implies that tide measurements must have been underway in September at least. In addition, a minute from General Walker to the Board (of Control of the East India Company) dated 11 July 1825, transcribed in Warner (1982), states "The Gentlemen of the Institution ... have commenced a series of observations on the tides similar to those which were some years ago made at Brest. This has been undertaken at the suggestion of Dr. Fallows ....”. Furthermore, Whewell (1833) refers to measurements by Johnson in September 1826. Consequently, there were undoubtedly measurements in progress prior to October 1826 but none of them have been preserved.

2. The findings reported in the last sentence are the reverse of those of the present paper, that the times are all late but the heights of rise and fall accord reasonably well with Maskelyne's.

3. The suggested measurements on the windward coast were never carried out, and indeed would have been almost impossible with the instrument available.

After his visit to Fallows, Johnson returned to St. Helena in March 1826; he was to pay another visit to the Cape Observatory in 1828. The site of the future St. Helena Observatory, 680 feet $(207 \mathrm{~m}$ ) high on Ladder Hill just south-west of Jamestown, had been decided upon, again with Fallows' approval, but there were inevitably long delays before it would be actually built and suitable telescopic equipment, clocks etc., installed in it. This work was only completed in late 1829 , when a regular programme of observation commenced. Meanwhile, Johnson had time to concentrate on his tide measurements.

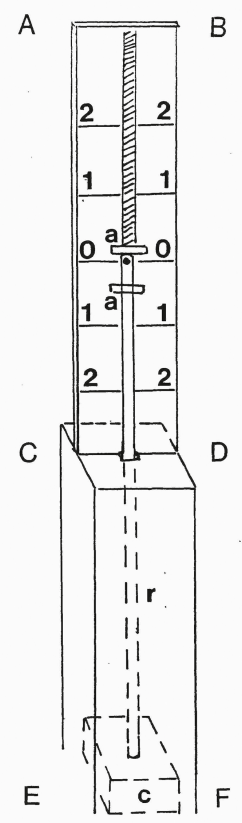

Figure 3. Johnson's tide recorder, redrawn from his original sketch.

Figure 1 is a rarity in showing both the Landing Place during the early part of the 20th century, where all tidal measurements have been made, and also the Observatory (indicated by an arrow). A striking feature is the straight rise of the railed stairway of 699 steps, known to the islanders as Jacob's Ladder. This stairway was built by the HEIC militia in 1828-1829 to facilitate transport of men and materials between Jamestown and various military buildings, including the Observatory. The name Ladder Hill pre-dates the building of Jacob's Ladder, as several entries in the Military Consultations before 1828 testify.

Astronomical observing eventually ceased when the British Crown took over the island's administration from the HEIC in 1834. The Observatory was used for a time as an Officer's Mess, but it was completely demolished by the middle of the 20th century, its stone having been used for other building projects. Since 1979, the derelict site has been marked by an engraved metal plaque, naming Walker and Johnson as co-founders of the erstwhile Observatory. The Landing Place has changed very little since the photograph, Fig. 1, was taken. Jacob's Ladder remains largely intact, and is still used by the more agile members of the island's population. 
4 Description of Johnson's tide gauge and its records

The following description of Johnson's tide gauge (Fig. 3) is copied verbatim from his manuscripts, hitherto unpublished:

ABCD is a graduated plank of wood, having a groove in the centre in which the two metal Indices a, a, are placed - a slight force is necessary to put the Indices in motion. To the plank is attached the box CDEF containing a rod of wood r, rendered buoyant by means of the cork [float] c; the rod moves in the direction of the groove through an opening in the top of the box, and communicates with the Indices by a small pin fixed perpendicularly to it at the upper end. An index is placed above and below the pin. In the lower part of the box, which is cased in copper, a few small apertures are made to admit the water. The rod rising with the tide moves the upper index with it to the highest point to which the water ascends, where the index will remain and show the high water mark. In the same manner, in retiring, the rod will carry the lower index to the lowest point to which the tide falls. Thus in case of the absence of the observer, the gauge will mark the greatest rise and fall of the tide. The gauge is placed near the sea in a well a few feet below the low water mark; the tide is admitted by a small channel cut through the rock; the water in the well is not in the least affected by the swell. N.B. The zero point from which the rise and fall of the tides have been reckoned is the centre of the plank.

The idea of using a well to which the sea is admitted through a few small holes was not new, having been advocated by Sir Robert Moray in the early years of the Royal Society (Moray, 1665). A similar arrangement of a buoyant float with vertical rod held in place by a tall wooden box had been devised by a hydrographer at Dunkirk named Baert (Cassini, 1710). These facts at least suggest that Johnson had access to scientific literature on the subject, possibly guided by Fallows. However, the use of sliding "Indices" to show maxima and minima seems to be entirely original in this context, as indeed is the whole concept of recording a relatively small tidal variation in the presence of sometimesheavy swell waves. The Indices would of course have to be read and re-set manually after each tide.

It was the invariable practice at that time to record only high tide and low tide, Maskelyne's experiment being a rare exception (Cartwright, 1999). Ironically, only a few years after Johnson, fully automatic recorders were devised to record all states of the tide; this made much more detailed tidal analyses possible. The weakest feature of recording extrema was the determination of the time of an extremum, since there is then by definition no vertical motion. The proper procedure was to choose an arbitrary level just below the level of an expected high tide, say, and time the passage of the sea rising past this level and again when falling past it, analogous to the usual method of determining the time of transit of a star across the meridian. The average of the two times is a good estimate of the time of high tide. Such a method has obvious deficiencies when wave oscillations are present and the tidal range is small. In fact, Johnson left no written account of what procedure was used. The results suggest that the procedure may have been changed occasionally, as discussed in Sect. 6.

In general, Johnson's phrase “... not in the least affected by the swell" lacks clarity, and one would have thought that the gauge must have responded to swell to some extent, probably with a significant time lag. Alongside the data for January and February 1827 there are several handwritten comments like "Tide stationary at High and Low Waters" for periods of 17-25 min. This could indicate occasional blocking of the well inlet, or variable friction in the sliding Indices. It may also account for the intermissions in recording, 14 March-10 April and 24 April-7 May, for which Johnson left no written explanation.

The recorded data in manuscript consist of the height above scale-zero and the depth below scale-zero for practically all the tides in the 13 months from October 1826, except for the short periods of intermission stated above. The heights were recorded in units of 1 in to the nearest quarter of an inch, so precision of about $6 \mathrm{~mm}$ can be assumed.

For the first 4 months, all these height and depth figures (typically four per day) were accompanied by estimated times, at first to the nearest $5 \mathrm{~min}$, later at figures not divisible by 5 , so presumably aspiring to $2-3$ min precision. We show in the next section that St. Helena Apparent Time was used. From February 1827, only two or three times are recorded each day, suggesting a degree of uncertainty in method or accuracy.

These heights and times of high and low waters are then followed in the manuscripts by columns headed "Height of Tide", which is nowadays better called the tidal range (height of the last high tide plus depth of the following low tide), and "Interval between Times of High Water", which is the difference between the time of a given high water and the preceding one. The values in these columns were calculated from the individual high and low water values, and so contain no extra information, other than as an arithmetic check on the manuscript entries. There then followed several columns of lunar orbital information for that day, including "Lunar Passage of the Meridian" which we refer to in the next section.

In the manuscripts are also three columns of brief verbal comments on the daily state of the wind, weather and surf (i.e. swell waves). The comments on wind are unlikely to be very relevant because of the shelter afforded by the steep cliffs everywhere (see Fig. 1), but the comments on surf (usually "low", "moderate" or "high") should give a good indication of how reliable the recorded heights and times were. Surf 
was "low" for most days in October-December 1826 and in June-July 1827, but "high" surf was more frequent in other months, especially February.

Finally, the Remarks column of the manuscripts included the times of the principal lunar phases, recorded by Johnson to the nearest minute, no doubt from his own calculations, which we refer to below. Such data are of course relevant to the interpretation of the tides.

\section{Ambiguity of time convention}

In any assessment of the tidal times the foremost question is: "What time convention was assumed?" At least three conventions could conceivably have been used:

a. Local Apparent (i.e. "sundial”) Time,

b. Local Mean Time,

c. Greenwich Mean Time (GMT).

Conventions (a) and (b) differ by the equation of time (EOT), which varied seasonally in the early 19th century from $-15 \mathrm{~min}$ (February) to $+16 \mathrm{~min}$ (November). (The EOT in the early 19 th century is the same as that of the present to within half a minute or less on all days of the year, see Hughes et al., 1989). Convention (b) is approximately $23 \mathrm{~min}$ earlier than (c) on account of the longitude of Jamestown, namely $5^{\circ} 43^{\prime} \mathrm{W}$.

The years of 1820-1840 comprised a period of transition in time-keeping (Howse, 1997). Fifty years earlier there would have been no doubt that (a) had been used (explicitly so in Maskelyne's tidal measurements); 50 years later than Johnson's it would more likely be (c). In 1834, when a time ball was erected at the St. Helena Observatory, it was officially lowered twice a day: once at 12:00 to mark noon, St. Helena Mean Time (convention b), then again at 13:00 Greenwich Mean Time (convention c) (Anonymous, 1835, which also includes an original sketch of the Observatory in its heyday; a copy of the same sketch appears in Warner, 1982, and elsewhere).

Sir John Lubbock complained of exactly the same dilemma in his famous analysis of the 19 years of high tides recorded at Liverpool in 1774-1792 by William Hutchinson (Lubbock, 1835; the ambiguity of the supposed time system is discussed on pages 275-276). Lubbock's dilemma was resolved by comparing Hutchinson's recorded times with a synthesis based on modern data for Liverpool. With the tidal synthesis in Mean Time, the differences (record - synthesis) showed obvious seasonal oscillations resembling the equation of time (Woodworth, 1999). Thus, it could be concluded that Local Apparent Time was used for the Liverpool recording.

We also have used a tidal synthesis based on modern data for St. Helena, but the same sort of test is not feasible on account of large fluctuations of the order of $1 \mathrm{~h}$ in Johnson's
Table 1. (a) TT (hours, minutes) indicates the Terrestrial Time of five new moons in 1826-1827 as given by modern theory, ET is the equation of time in minutes for the given dates, AT is Apparent Time for new moon at Jamestown, resulting from the adjustment (TT + ET - 22.9), which may be compared to MJ, which is Johnson's computed time of new moon as noted in his manuscripts. (b) Corresponding times of five full moons.

\begin{tabular}{rrrrrr}
\hline (a) & & TT & ET & AT & MJ \\
\hline 1826 & 1 Oct & 1518 & +11 & 1506 & 1506 \\
& 31 Oct & 0105 & +16 & 0058 & 0059 \\
1827 & 27 Jan & 0958 & -13 & 0922 & 0923 \\
& 25 Feb & 2226 & -13 & 2150 & 2151 \\
& 24 Jul & 0049 & -06 & 0020 & 0021 \\
\hline (b) & & TT & ET & AT & MJ \\
\hline 1826 & 15 Oct & 2131 & +14 & 2122 & 2123 \\
1827 & 11 Feb & 2237 & -15 & 2159 & 2200 \\
& 13 Mar & 1217 & -10 & 1145 & 1146 \\
& 11 May & 0820 & +04 & 0801 & 0802 \\
& 5 Sep & 1434 & +01 & 1412 & 1413 \\
\hline
\end{tabular}

recorded times, to be discussed below. Fortunately, Johnson provided another set of times in his records of new, full and quarter moons. For comparison with these, we have computed the times of the same events using recent algorithms by Meeus (1999) based on the modem lunar theory by Chapront. The Meeus algorithms give the phase times in Terrestrial Time (the modern successor to Ephemeris Time), which in 1826-1827 differed by only a few seconds from Universal Time, the modern equivalent of Greenwich Mean Time. To these we have added (equation of time - $22.9 \mathrm{~min}$ ), to reduce them to St. Helena Apparent Time. (The EOT here assumes the astronomical convention, for example positive in November, manuals of navigation frequently giving the opposite sign.) Table 1a, b compare the resulting times with those computed by Johnson for five new moons and five full moons.

In Table $1 \mathrm{a}, \mathrm{b}$ the date is followed by a column headed TT (hours, minutes), which is the Terrestrial Time as required by the modern lunar theory. The column headed ET is the computed equation of time in minutes for the given dates. AT is Apparent Time for Jamestown, resulting from the adjustment: (TT + ET - 22.9), and MJ is the computed time written out by Johnson. (The time for the full moon of 11 May was actually written "802 pm" instead of "am", presumably due to a slip of the pen.) The closeness of agreement between the last two columns of figures, despite variations of ET between -15 to +16 min confirms that Johnson kept his lunar information in Local Apparent Time and suggests that he used the same time convention for his tidal measurements.

The manuscripts note the times of 48 new, full and quarter moons in all, each computed by Johnson, and each consistent with being in local apparent time, as demonstrated by the 10 
examples in Table 1a, b. In addition, alongside the columns of heights above and depths below scale-zero, and the times of high and low waters, is a column headed "Time of Lunar Passage of the Meridian", containing the times of lunar transit on that day. These will also have been computed by Johnson, and all 396 entries are consistent with being in local apparent time. It is inconceivable that Johnson would have employed two conventions for time in adjacent columns on the same page, so we conclude that local apparent time must have been used for the times of high and low waters.

\section{Times of high and low tide}

As mentioned above, we have made use of a tidal synthesis (i.e. a hindcast) for 1826-1827 based on sea level measurements made at Jamestown over the period 1993-2006. These measurements were made using a "B gauge", a type of accurate tide gauge constructed by NOC (Woodworth et al., 1996). The synthesis is based on a harmonic analysis of 57 harmonic terms with continuous adjustment for the position of the lunar node. It may be confidently trusted as a hypothetical record of what Johnson would have recorded, given a perfect instrument and in the absence of the effects of swell and of random variations of the tide itself. The latter variation may be judged by the residual (non-tidal) variance in the modern sea level record of $8.4 \mathrm{~cm}^{2}$ (standard deviation of $2.9 \mathrm{~cm}$ ) which can be assigned as an upper limit to the random tidal variations. Given the total variance of the tide at Jamestown of approximately $650 \mathrm{~cm}^{2}$, this translates into a standard deviation of variations in the times of high or low tide relative to those of the synthesis of about $13 \mathrm{~min}$.

It should be remembered that no such idealised synthesis was available to Johnson, except the Establishment rule (Pugh and Woodworth, 2014), whereby high tide at Jamestown follows the upper and lower transits of the moon by about $130-150 \mathrm{~min}$. Maskelyne's record was too short to make a reliable prediction possible by methods known at that time. So Johnson was not in a position to judge whether his recorded times were reasonable or not, especially given his general lack of experience in such matters.

The two tides for each day are of course identifiable without ambiguity in both recorded data and in the synthesis. We can denote the differences in time between them as follows:

$\mathrm{dt}=$ measured time - synthetic time,

where "measured time" means the time recorded by Johnson corrected for both the equation of time and for the longitude of St. Helena, so as to be adjusted into Greenwich Mean Time for comparison to the "synthetic time".

Figure 4a shows values of dt for the whole record for high and low waters. Values seem to be characterised by sequences for which $\mathrm{dt}$ is reasonably small (that is, mostly within $\pm 30 \mathrm{~min}$ ), interspersed by sequences for which dt is consistently greater than $\mathbf{3 0 - 9 0 ~ m i n . ~ I t ~ i s ~ a s ~ i f ~ t h e ~ i n l e t ~ h o l e s ~}$ (a)

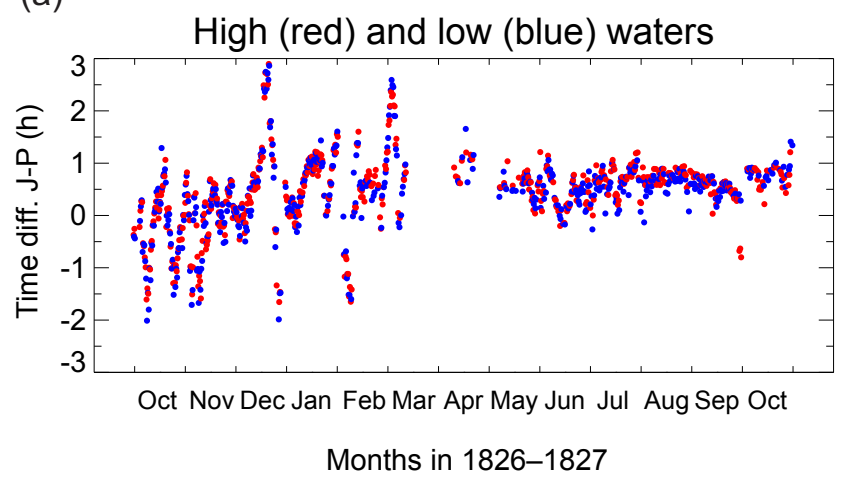

(b)

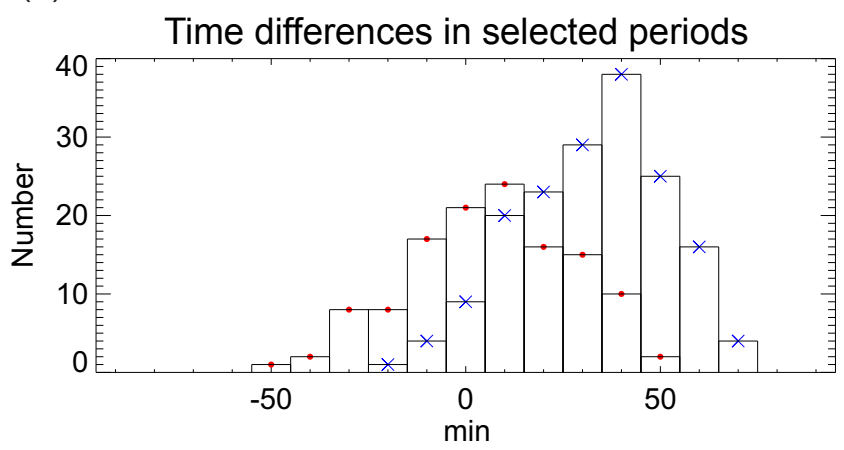

Figure 4. (a) Differences between times of high and low waters as measured by Johnson and as predicted by the modern synthesis (JP). (b) Histograms of time differences in minutes for 11 November12 December 1826 (red dots) and 1 June-31 July 1827 (blue crosses).

to the stilling well were intermittently blocked, thus altering the time lag of the device. Figure $4 \mathrm{a}$ shows that, although dt varies considerably through the record, similar values are obtained for high and low waters at any one time, with an average value of $25 \mathrm{~min}$ overall.

The largest variations of $\mathrm{dt}$ are obtained during December 1826 and early March 1827, during which there are occasional strange sequences of recorded times. As an extreme example, the evening high tides and morning low tides for the week 21-27 December 1826 are shown in Table 2, where MJ is the time recorded by Johnson in Local Apparent Time, and $\mathrm{dt}$ the difference from the synthesis as defined above. Anyone familiar with tide tables or instrumental records of tides will know that a sequence of five consecutive low tides advancing in time by less than an hour in total, and a similar sequence of six high tides, in calm conditions ("low surf"), is unheard of and practically impossible in a lunar tidal regime, especially when one tide in both sequences is earlier in the day than its predecessor. The differences dt thereby show a dramatic decline from positive to negative values. A handwritten note on 26 December, “This day's observations are 
Table 2. Sequence of anomalous tide times. The evening high tides and morning low tides for the week 21-27 December 1826. MJ is Johnson's recorded value for the time of the tide in Local Apparent Time (hours, minutes), $\mathrm{dt}$ is the difference from the synthesis in minutes, as described in the text.

\begin{tabular}{|c|c|c|c|c|c|}
\hline & & \multicolumn{2}{|c|}{$\begin{array}{l}\text { Morning } \\
\text { Low tide }\end{array}$} & \multicolumn{2}{|c|}{$\begin{array}{l}\text { Evening } \\
\text { High tide }\end{array}$} \\
\hline & & MJ & $\mathrm{dt}$ & MJ & $\mathrm{dt}$ \\
\hline \multirow[t]{7}{*}{1826} & $21 \mathrm{Dec}$ & 0323 & +156 & 2120 & +106 \\
\hline & $22 \mathrm{Dec}$ & 0330 & +101 & 2205 & +87 \\
\hline & $23 \mathrm{Dec}$ & 0411 & +70 & 2248 & +64 \\
\hline & $24 \mathrm{Dec}$ & 0458 & +43 & 2235 & -16 \\
\hline & $25 \mathrm{Dec}$ & 0445 & -36 & 2232 & -80 \\
\hline & $26 \mathrm{Dec}$ & 0450 & -87 & 2255 & -112 \\
\hline & $27 \mathrm{Dec}$ & 0508 & -119 & 2410 & -88 \\
\hline
\end{tabular}

not to be depended upon", is not very helpful in the absence of any explanation.

After 27 December, the times (but not the heights) were discontinued for 3 days. When full recording resumed on 31 December, the differences dt reverted to more usual values, around +10 to $40 \mathrm{~min}$, which is more understandable. Possibly some instrumental adjustment was made, or the method used for time-keeping was changed.

However, Fig. 4a shows that there are some relatively long periods of uniformity in time difference dt. One such period, 11 November-12 December had a full set of 62 highs and 62 lows recorded, with dt in the range -52 to $+47 \mathrm{~min}$. Its histogram is depicted in Fig. 4b (red dots). The average time delay $\mathrm{dt}$ is $+6.1 \mathrm{~min}$, and this could well be a typical lag of the stilling well for tidal periods. The standard deviation, $21.3 \mathrm{~min}$, is an acceptable sampling variability for such a small range of the vertical rise and fall.

Another extended period of uniformity could be said to be from May 1827 onwards. For example, if one considers the complete months June-July 1827 , dt values in the range -16 to $+73 \mathrm{~min}$ are obtained. The resulting histogram of 169 times ( 80 highs, 89 lows) is shown in Fig. 4b (blue crosses). The mean time lag has here increased to $32.7 \mathrm{~min}$, with an increase in skewness, but the standard deviation about the mean is $18.9 \mathrm{~min}$, about the same as in the earlier example. The salient figures concern the increase in the average delay of about $27 \mathrm{~min}$. This is likely to be due to increased restriction to the flow, difficult to control in an exposed location subject to growth of marine organisms.

There is an intriguing postscript to be added to this discussion, in that if Johnson's recorded times of high and low waters had in fact been given in GMT, with no necessity for the equation of time and 22.9 min adjustments, then they would have been in better overall agreement with the synthetic times. However, this possibility is just not feasible, given that there is no evidence that the recorded times were other than in local apparent time, as explained above. Consequently, this observation has to remain as a curiosity of the timings in Johnson's data.

\section{Accuracy of tidal ranges and high and low water heights}

Turning now to height measurements, we get much better agreement with the hindcast synthesis. First, we compared values of the tidal range (that is, height of a high tide plus depth of the following low tide) to synthetic values. These values are, of course, independent of the arbitrary zero-datum level used in the Johnson's measurements. Second, we compared values of the individual high and low tides to those of the synthesis. From the mean differences between heights above and depths below zero, it appears that that arbitrary datum was set approximately $8.3 \mathrm{~cm}$ above the true mean tide level. All comparisons are shown here in metric units (cm) rather than the imperial units (inches) used by Johnson, which is more appropriate for a modern treatment of the data.

Figure 5a compares the recorded tidal ranges with the corresponding synthetic values for the entire record. Generally excellent correspondence can be seen for most of the record, although the Johnson values clearly underestimate those of the synthesis in sections of data, including the last 2 months of the record. Figure $5 \mathrm{~b}$ provides a focus on two typical 30-day periods. Each period comprises 58 consecutive tidal ranges (high to following low) occupying about $6.2 \mathrm{~h}$ on average, followed by another $6.2 \mathrm{~h}$ while the tide rises again to its next maximum, i.e. half a lunar day in total. The upper part of Fig. 5b starts with a new moon on 1 October 1826 , and the lower part starts with a full moon on 9 June 1827; they are separated by an offset of $50 \mathrm{~cm}$ to avoid confusion. Both initial dates were near perigee (moon closest to earth), which accounts for their high initial range; lower maxima occur 29 tides (15 days) later, when the moon is close to apogee (furthest from earth).

The total observed variations in range from 37 to $108 \mathrm{~cm}$ in these two periods is large enough to show the overall goodness of fit of observations to the synthesis. The standard deviations of the differences between Johnson and synthesis values in the two periods are 3.6 and $5.3 \mathrm{~cm}$ respectively. These figures are very respectable given that, as mentioned above, the standard deviation of non-tidal sea level variability at St. Helena is of the order of $2.9 \mathrm{~cm}$, and also given the evident crudity of Johnson's instrument. During the first half of the second period, the recorded ranges are systematically lower than the synthetic values, a situation that becomes even more apparent towards the end of the record (Fig. 5a). One can conjecture that this is probably due to a blockage to the inlet of the instrument in the middle of 1827, already noted through the increase of time lag from that in 1826. Otherwise, one might have expected the use of the Indices in the presence of waves (in spite of a stilling well) to lead naturally 
(a)

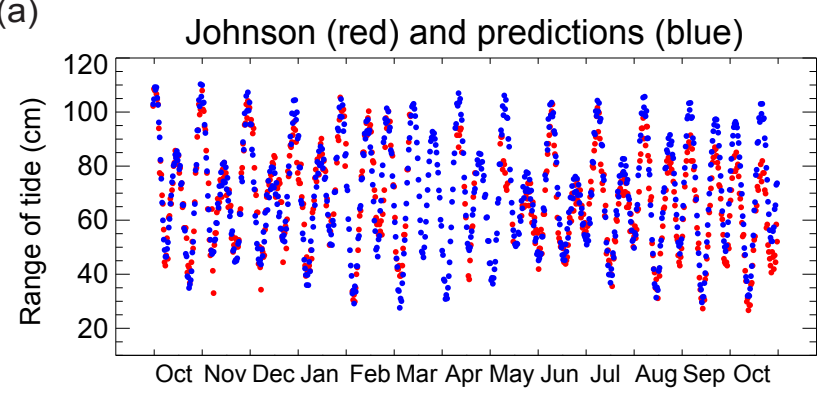

Months in 1826-1827

(b)

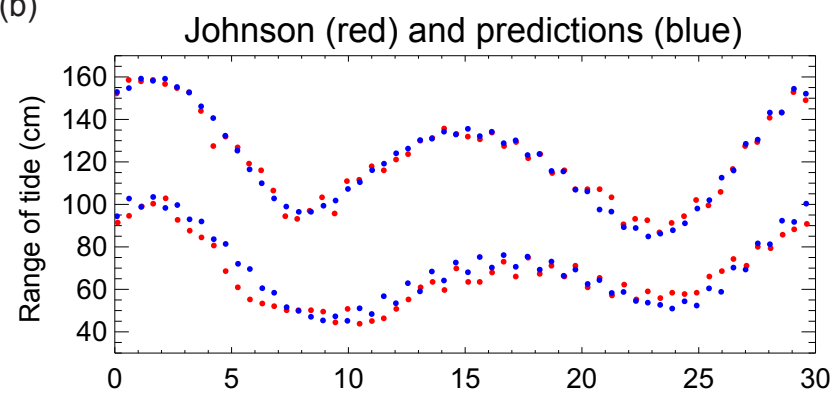

Days in selected 30-day periods in 1826-1827

(c)

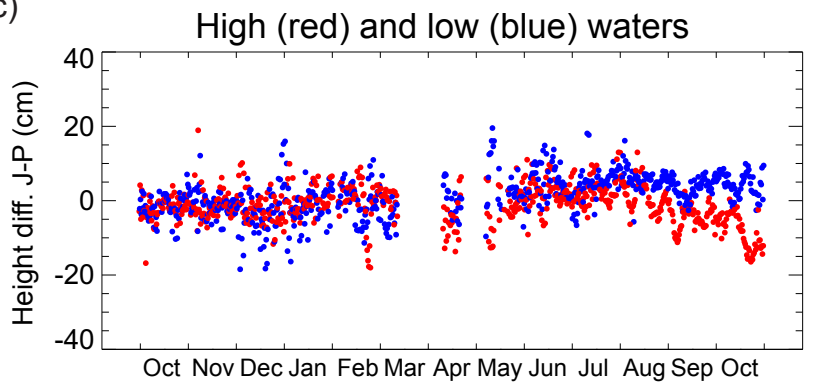

Months in 1826-1827

Figure 5. (a) Tidal ranges as measured by Johnson and as predicted by the modern synthesis. (b) A focus on two 30-day periods starting 1 October 1826 and 9 June 1827. An offset of $50 \mathrm{~cm}$ has been added to the ranges for October for plotting clarity. (c) Differences between heights of high and low waters as measured by Johnson and as predicted by the modern synthesis (J-P).

to higher recorded ranges than expected, which does not appear to have been the case at any point in the record.

The daily oscillation in range, especially pronounced in the middle of the lower set of data in Fig. 5b, is due to the daily component of the tide, sometimes called the diumal inequality, usually highest at the summer solstice, as here. There is some consistency in the oscillation between data and synthesis, but less so than in the main 15-day oscillation from spring to neap tides, because of the lower signal-to-noise ratio.
Figure 5c compares the individual heights of high and low waters from Johnson's data to those of the synthesis. In each case, we have removed the average height for the whole record, thereby avoiding the problem of having different datums in the measurements and predictions. The high and low water height-difference values have standard deviations of 5.1 and $5.5 \mathrm{~cm}$ respectively. These values demonstrate once again what was a respectable measurement accuracy for the heights of the tide in such a high wave environment, if not for the times described in Sect. 6. Difference values for high tide can be seen to decrease in the latter part of the record, while those for low tide increase to some extent, which confirms the observation of reduced tidal range in the observations at this time (Fig. 5a), as mentioned above, and results in the slightly larger standard deviation for low waters.

\section{Conclusions}

The tidal record kept by Manuel Johnson and his assistants was an original and time-consuming effort, requiring attention to timing, and regular reading and re-setting of the Indices, day and night for 13 months, excepting a few weeks of (unexplained) intermission in March, April and May 1827. As we have seen, Johnson probably obtained the idea of recording the tides from Fallows during his visit to the Cape in early 1826 , as a useful scientific occupation while waiting for the St. Helena Observatory to be constructed and equipped. The instrument itself seems to have been Johnson's own invention, and it was the first time such a device had ever been mounted at a site so exposed to heavy ocean swell. (A mechanism for recording maxima and minima with some similarity to Johnson's, but in a float and stilling well gauge, was later to be employed in Ireland by Haughton, 1856).

Johnson's calculated times of full, new and quarter moons are surprisingly accurate for the period, mostly to a minute of time (see Cook, 1988, chap. 5-6). They supply a useful confirmation that Local Apparent Time was used in the tidal $\log$. This fact is important in evaluating the recorded times of high and low tides relative to a synthesis based on recent data. There is no indication how these times were measured in the first place, but it appears safe to assume that all due care was taken within the limitations of the recording equipment. They are in fact highly variable with a strong tendency to lag, sometimes by more than an hour (Fig. 4a). The most likely cause is varying restriction to the flow of seawater into the pipe in which the cork float was suspended (Fig. 3). Johnson's own assessment, that the water level was "not in the least affected by the swell", was probably the Achilles' heel of the whole system as far as the tidal times were concerned.

On the other hand, the tidal ranges, effectively doubleamplitudes, agree reasonably well with the hindcast synthesis (Fig. 5), with typical standard deviations averaged over a month of about $5 \mathrm{~cm}$ ( 2 inches). Some of this deviation must be attributed to the natural random variation in the tide itself. 
During the latter part of 1827 there is evidence that the measured tidal range was attenuated, primarily due to a reduction in measured high tide, again presumably due to technical issues to do with the tide gauge such as restriction to the inlet. The diurnal variation with maximum excursion $\pm 2.5 \mathrm{~cm}$ ( 1 inch) is discernibly recorded, but being comparable in amplitude with the general noise level, derivation of a meaningful measure of the diurnal tide from Johnson's data would require careful filtering of a long record.

Unfortunately, the poor timing performance considerably detracts from the value of the record as a whole. Maskelyne's 1761 measurements, with their precise timing and carefully averaged heights, remain the most valuable record before the late 20th century, despite their relatively short duration (Cartwright, 1971b). Within a decade of Johnson's exercise, the technique of tide recording had been revolutionised by automatic devices giving a continuous profile of sea level with clockwork timing. These instruments rendered obsolete the recording of mere high and low tides, and led to the powerful predictive technique of Harmonic Analysis at the end of the 19th century (Cartwright, 1999; Pugh and Woodworth, 2014). Nevertheless, the old records such as Johnson's are worth preserving despite their limitations as more material for studies of long-term changes in the tide (Cartwright, 1971b). It is conceivable that a future analyst in "data archaeology" may be able to derive further benefit from them. It is a pity that nobody, apparently, has examined Johnson's record before. A timely critical appraisal might have stimulated a rerun of the exercise with improved instrumentation during the 19th century. But this was impossible without a respectable publication of the original data.

By 1829 Manuel Johnson was fully embarked on his career as an astronomer. In 1834 he resigned his post at St. Helena and returned to Europe in search of wider experience. He was elected Fellow of the Royal Society in 1856 and was President of the Royal Astronomical Society in 1855-1857. With the Crown taking over the island from the HEIC soon after Johnson left, all further educational activity and scientific observing virtually ceased for reasons of economy, except for a magnetic observatory set up for a time by the Royal Society of London, and occasional visits by geophysical research expeditions (Tatham and Harwood, 1974). A tidal scientist may take consolation from the fact that barometric observations in 1842 made at Longwood House (where Napoleon died in 1821) first demonstrated the existence of a lunar tide in the atmosphere. This discovery was actually made by a Captain Lefroy of the Royal Artillery, but the results were communicated to the Royal Society by Lt. Colonel Edward Sabine, later to be President. Sabine (1847) quotes some rough statistics for the ocean tide at St. Helena, "made in 1827 under the direction of Major-General Walker". These ocean tide observations, and the small number of observations which Whewell (1833) mentions as having been provided to him by Walker "at the request of Dr. Fallows", can only have been taken from the measurements by John- son during 1826-1827. Walker's term as Governor ended in 1828. As far as we know, these are the only studies in which Manuel Johnson's tidal observations have ever been used, until now.

\section{Notes}

Dr. David Cartwright, FRS, wrote a first draft of this paper, having been aware for many years of the importance of Manuel Johnson's measurements within the history of tidal science. After he died in 2015, it was necessary for Woodworth and Ray to revisit much of Cartwright's earlier work. That required Johnson's tabulations to be copied once again from the manuscripts at Cambridge University Library into computer files, and for the analyses to be repeated. The present paper has modified and added figures to Cartwright's original draft and sections of text have been updated, but otherwise the paper is as he intended it. The new data files will be lodged with the British Oceanographic Data Centre so any future researcher can use them.

Data availability. The data can be accessed via doi:10.5285/4b2b52d7-ffd9-2473-e053-6c86abc0103b (Cartwright et al., 2017).

Competing interests. The authors declare that they have no conflict of interest.

Acknowledgements. We thank Bob Spencer, Peter Foden, Jeff Pugh and colleagues at NOC for their maintenance of the St. Helena tide gauge installation. We are grateful to Alan Hudson of St. Helena, Adam Sizeland from the St. Helena Museum, and the staff of Cambridge University Library for their help with this project. This work was undertaken when PLW was an Honorary Research Fellow at the National Oceanography Centre in Liverpool in receipt of an Emeritus Fellowship from the Leverhulme Trust. Part of this work was funded by UK Natural Environment Research Council National Capability funding.

Edited by: M. Ertsen

Reviewed by: G. A. Good and one anonymous referee

\section{References}

Airy, G. B.: Tides and waves, Encyclopædia Metropolitana, London, 5, 241-396, 1845.

Anonymous: Extract of a journal of the tides kept at St. Helena by Lieut. Johnson R. N. (sic), communicated by the Rev. Fearon Fallows, M. A., Quarterly Journal of Science, Literature, and Art, The Royal Institution of Great Britain, 1, 172-178, 1829.

Anonymous: The time ball of St. Helena, The Nautical Magazine, 4, 653-660, 1835. 
Cartwright, D. E.: Tides and waves in the vicinity of St. Helena (with an appendix by John S. Driver), Philos. T. Roy. Soc. Lond., 270, 603-646, doi:10.1098/rsta.1971.0091, 1971a.

Cartwright, D. E.: Some ocean tide measurements of the eighteenth century, and their relevance today, P. R. Soc. Edinb. B, 72, 331339, doi:10.1017/S0080455X00001892, 1971b.

Cartwright, D. E.: Tides: a scientific history, Cambridge, Cambridge University Press, 292 pp., 1999.

Cartwright, D. E., Woodworth, P. L., and Ray, R. D.: Tabulations of ocean tide at St. Helena, 1826-1827, British Oceanographic Data Centre - Natural Environment Research Council, UK, doi:10.5285/4b2b52d7-ffd9-2473-e053-6c86abc0103b, 2017.

Cassini, J.: Reflexions sur les observations du flux et du réflux de la mer faites á Dunquerque par M. Baert, 1701-1702, L'Histoire et Les Mémoires de l'Académie Royale des Sciences, 318-341, 1710.

Cook, A. H.: The motion of the Moon, Bristol, Adam Hilger, 236 pp., 1988.

Cook, A. H.: Edmond Halley: Charting the heavens and the seas, Oxford, Clarendon Press, 556 pp., 1998.

Haughton, S.: The solar and lunar diurnal tides on the coasts of Ireland, Transactions of the Royal Irish Academy, 23, 35-139, available at: http://www.jstor.org/stable/30079307 (last access: 1 March 2017), 1856.

Howse, D.: Greenwich time and the longitude, London, Philip Wilson Publishers Ltd., 208 pp., 1997.

Hughes, D. W., Yallop, B. D., and Hohenkerk, C. Y.: The equation of time, Mon. Not. R. Astron. Soc., 238, 1529-1535, doi:10.1093/mnras/238.4.1529, 1989.

Jackson, E. L.: St. Helena: the historic island, from its discovery to the present date, London, Ward, Lock and Co., 452 pp., 1903.

Johnson, M. J.: A catalogue of 606 principal fixed stars made in the Southern Hemisphere at The Observatory, St. Helena from November 1829 to April 1833, London, The Royal Astronomical Society, 82 pp., 1835.

Lalande, J. J.: Astronomie, Tome 4, p. 342, 1781.

Lubbock, J. W.: Discussion of tide observations made at Liverpool, Philos. T. Roy. Soc. Lond., 125, 275-299, doi:10.1098/rstl.1835.0017, 1835.

Maskelyne, N.: Observations on the tides in the island of St. Helena, Philos. T. Roy. Soc. Lond., 52, 586-606, doi:10.1098/rstl.1761.0100, 1761.
Meeus, J.: Astronomical Algorithms, Richmond, Virginia, Willman-Bell, Inc., 477 pp., 1999.

Military Consultations: Military Consultations of the Government of St. Helena (1824-28), Meeting of 2 October 1826, London, British Library, India Office Records and Private Papers, Reference IOR/G/32/105, 659-660, 1826.

Moray, R.: Considerations and enquiries concerning tides, by Sir Robert Moray; Likewise for a further search into Dr. Wallis's Newly Publish't Hypothesis, Philos. T. Roy. Soc. Lond., 1, 298 301, doi:10.1098/rstl.1665.0113, 1665.

Pugh, D. and Woodworth, P.: Sea-level science: Understanding tides, surges, tsunamis and mean sea-level changes, Cambridge, Cambridge University Press, 395 pp., 2014.

Sabine, E.: On the lunar atmospheric tide at St. Helena, Philos. T. Roy. Soc. Lond., 137, 45-50, doi:10.1098/rstl.1847.0005, 1847.

Spencer, R., Foden, P. R., McGarry, C., Harrison, A. J., Vassie, J. M., Baker, T. F., Smithson, M. J., Harangozo, S. A., and Woodworth, P. L.: The ACCLAIM programme in the South Atlantic and Southern Oceans, Int. Hydrogr. Rev., 70, 7-21, 1993.

Tatham, W. G. and Harwood, K. A.: Astronomers and other scientists on St. Helena, Ann. Sci., 31, 489-510, doi:10.1080/00033797400200421, 1974.

Warner, B.: Manuel Johnson and the St. Helena observatory, Vistas in Astronomy, 25, 383-409, doi:10.1016/0083-6656(81)900659, 1982

Warner, B.: Royal Observatory, Cape of Good Hope, 1820-1831: The founding of a Colonial Observatory, Dordrecht, Kluwer Academic Publishers, 241 pp., 1995.

Whewell, W.: Essay towards a first approximation to a map of cotidal lines, Philos. T. Roy. Soc. Lond., 123, 147-236, doi:10.1098/rstl.1833.0013, 1833.

Woodworth, P. L.: A study of changes in high water levels and tides at Liverpool during the last 230 years with some historical background, Proudman Oceanographic Laboratory Report, No. 56, Birkenhead, Proudman Oceanographic Laboratory, 62 pp., available at: http://nora.nerc.ac.uk/3916/ (last access: 1 March 2017), 1999.

Woodworth, P. L., Vassie, J. M., Spencer, R., and Smith, D. E.: Precise datum control for pressure tide gauges, Mar. Geod., 19, 120, 1996 